\title{
Platelet-fibrin clot strength measured by thromboelastography could predict hypercoagulability and antiplatelet effects in patients after percutaneous coronary intervention
}

\author{
Xiao-Qin Yan ${ }^{1,2,3 \#}$, Chi Zhang ${ }^{3 \#}$, Hong-Yao Shi ${ }^{4 \#}$, Ling-Cong Kong ${ }^{3}$, Li Liu ${ }^{5}$, Zhi-Chun Gu ${ }^{3}$, Qing Zhu ${ }^{1}$ \\ ${ }^{1}$ School of Pharmacy, Nantong University, Nantong, China; ${ }^{2}$ Department of Pharmacy, Shanghai Pudong Hospital, Shanghai, China; ${ }^{3}$ Department \\ of Pharmacy, Renji Hospital, School of Medicine, Shanghai Jiao Tong University, Shanghai, China; ${ }^{4}$ Department of Laboratory Medicine, Shanghai \\ Pubin Children's Hospital, Shanghai, China; ${ }^{5}$ Department of Emergency, Renji Hospital, School of Medicine, Shanghai Jiao Tong University, \\ Shanghai, China \\ Contributions: (I) Conception and design: ZC Gu, XQ Yan, Chi Zhang; (II) Administrative support: ZC Gu, L Liu, Q Zhu; (III) Provision of study \\ materials or patients: C Zhang, XQ Yan; (IV) Collection and assembly of data: XQ Yan, HY Shi; (V) Data analysis and interpretation: ZC Gu, HY \\ Shi; (VI) Manuscript writing: All authors; (VII) Final approval of manuscript: All authors. \\ "These authors contributed equally to this work, and should be considered as co-first authors. \\ Correspondence to: Zhi-Chun Gu, MD. Department of Pharmacy, Renji Hospital, School of Medicine, Shanghai Jiao Tong University, Shanghai \\ 200127, China. Email: guzhichun213@163.com; Li Liu, MD. Department of Emergency, Renji Hospital, School of Medicine, Shanghai Jiao Tong \\ University, Shanghai 200127, China. Email: lily_1231@126.com.
}

Backgroundk It has been estimated that nearly one-fifth post-percutaneous coronary intervention (PCI) patients treated with clopidogrel continued to have recurrent thrombotic events, which implied the limitation of "one-size-fits all" strategy for antiplatelet therapy.

Methods: From July 2017 to April 2019, patients with acute coronary syndrome [ACS, including unstable angina (UA), non-ST segment elevation myocardial infraction (NSTEMI), and ST segment elevation myocardial infraction (STEMI)] or old myocardial infarction (OMI), or patients without coronary heart disease (non-CAD) were retrospectively enrolled in this study. For CAD patients undergoing PCI, standard dual antiplatelet therapy (100 mg aspirin and $75 \mathrm{mg}$ clopidogrel) was prescribed. After administration of dual antiplatelet agents for at least 5 days, whole blood samples were collected and platelet function was tested using thrombelastography (TEG). Thrombin-induced platelet-fibrin clot strength $\left(\mathrm{MA}_{\text {thrombin }}\right)$ and ADPinduced platelet-fibrin clot strength $\left(\mathrm{MA}_{\mathrm{ADP}}\right)$ were measured to assess the hypercoagulability and antiplatelet effects.

Results: A total of 571 patients, including 479 ACS patients, 21 OMI patients and 71 non-CAD patients were enrolled. Highest level of $\mathrm{MA}_{\text {thrombin }}$ was detected in STEMI patients, while lowest $\mathrm{MA}_{\text {thrombin }}$ level was observed in non-CAD patients $(\mathrm{P} 1<0.05$ for OMI vs. non-CAD; $\mathrm{P} 2<0.001$ for ACS vs. non-CAD; $\mathrm{P} 3<0.05$ among ACS). Higher $M_{A D P}$ was also observed in STEMI and NSTEMI patients compared with UA patients $(\mathrm{P}<0.001)$. When $\mathrm{MA}_{\mathrm{ADP}}$ was divided into trisections $\left(\mathrm{MA}_{\mathrm{ADP}}<31 ; 31-47 ;>47 \mathrm{~mm}\right)$, a considerable portion of $41.8 \%$ ACS patients were in the first trisection $\left(\mathrm{MA}_{\mathrm{ADP}}<31 \mathrm{~mm}\right.$ ), containing $50.4 \%$ of UA patients, $35.7 \%$ of NSTEMI patients and $26.5 \%$ of STEMI patients, with significant difference being observed between UA patients and other ACS patients $(\mathrm{P}<0.05$ for NSTEMI vs. UA; $\mathrm{P}<0.001$ for STEMI vs. UA). Meanwhile, $27.6 \%$ of NSTEMI and $31.0 \%$ of STEMI patients were in the third trisection $\left(\mathrm{MA}_{\mathrm{ADP}}\right.$ $>47 \mathrm{~mm})$, which was significantly higher than that of UA patients $(12.7 \%)(\mathrm{P}<0.001$ for NSTEMI or STEMI vs. UA).

Conclusions: Considering various degrees of hypercoagulability and antiplatelet effects of clopidogrel among OMI and ACS patients post-PCI. More attention should be paid to personalized antiplatelet therapy according to individual's effects of $\mathrm{P} 2 \mathrm{Y}_{12}$ receptor inhibitors.

\footnotetext{
$\wedge$ ORCID: 0000-0002-1245-9690.
} 
Keywords: Acute coronary syndrome (ACS); platelet activation; thrombelastography (TEG); percutaneous coronary intervention (PCI); clopidogrel

Submitted Aug 27, 2019. Accepted for publication Nov 17, 2020.

doi: 10.21037/apm-20-1728

View this article at: http://dx.doi.org/10.21037/apm-20-1728

\section{Introduction}

It is well understood that platelets play a pivotal role in maintaining a balance between haemostasis and bleeding in coronary artery thrombosis (1). Dual antiplatelet therapy (DAPT) with aspirin and $\mathrm{P} 2 \mathrm{Y}_{12}$ receptor inhibitors is the current standard for acute coronary syndrome (ACS) patient or those undergoing percutaneous coronary intervention (PCI) to prevent thromboembolic events $(2,3)$. Currently, clopidogrel is still the most widely used $\mathrm{P} 2 \mathrm{Y}_{12}$ receptor inhibitor for secondary cardiovascular disease prevention, whose beneficial effects in post-PCI patients has been demonstrated in Clopidogrel for the Reduction of Events During Observation (CREDO) and Percutaneous Coronary Intervention-Clopidogrel in Unstable angina to prevent Recurrent ischemic Events (PCI-CURE) studies $(4,5)$. Nevertheless, it has been estimated that nearly onefifth post-PCI patients treated with clopidogrel continued to have recurrent thrombotic events, which implied the obvious limitation of "one-size-fits all" strategy for antiplatelet therapy (6). High thrombin induced clot strength in whole blood now was considered associated with increased risk of recurrent thromboembolic events in patients undergoing PCI (7). ACS comprises three symptomatic manifestations, including unstable angina (UA), non-ST segment elevation myocardial infraction (NSTEMI) and ST segment elevation myocardial infraction (STEMI), and patients of each manifestation might present different degrees of hypercoagulability (8). It is speculated that different antiplatelet therapies should be given to patients according to individual's hypercoagulability and antiplatelet effects of $\mathrm{P} 2 \mathrm{Y}_{12}$ receptor inhibitors. However, scarce knowledge was understood in this field. This study therefore aims to understand the individual's hypercoagulability and antiplatelet effects of clopidogrel in ACS patients by using thrombelastography (TEG, which has been increasingly utilized to graphically illustrate overall coagulation status). We present the following article in accordance with the STROBE reporting checklist (available at http://dx.doi.org/10.21037/apm-20-1728).

\section{Methods}

\section{Patient selection}

From July 2017 to April 2019, patients with a diagnosis of ACS or old myocardial infarction (OMI), or patients without coronary heart disease $(\mathrm{CAD})$ were retrospectively enrolled in this study. ACS were further grouped according to the manifestations, including UA, NSTEMI, and STEMI. OMI was defined as the patients who suffered myocardial infarction after 2 months. Patients without CAD (control group) were healthy patients on physical examinations. The exclusion criteria were as follows: a history of serious anemia; malignant disease; serious renal or hepatic insufficiency; total platelet count $<100 \times 10^{9} / \mathrm{L}$, hematocrit $<30 \%$, and age $<18$ years. The study was conducted in accordance with the Declaration of Helsinki (as revised in 2013). This study was approved by Ethics Committee of Renji Hospital, School of Medicine, Shanghai Jiao Tong University (\#2018-025). Written informed consent was obtained from the patients for publication of this study.

\section{Procedure and medication protocol}

Coronary arteriography (CAG) and PCI were conducted in included ACS and OMI patients, and loading doses of aspirin $(300 \mathrm{mg})$ and clopidogrel $(300 \mathrm{mg})$ were given to those patients before CAG. Stent type was chosen by the operator after CAG. Standard DAPT (100 mg aspirin and $75 \mathrm{mg}$ clopidogrel) was prescribed for at least 1 year. Maintenance therapy with $100 \mathrm{mg}$ aspirin and $75 \mathrm{mg}$ clopidogrel were already given to other patients except for control patients in this study. All interventions were performed according to the current guideline (9).

\section{TEG and platelet aggregation analysis}

After administration of DAPT for at least 5 days, whole blood samples were collected by nursing staff and drawn into a vacutainer tubes containing $3.2 \%$ trisodium citrate. Platelet rich plasma was obtained after centrifugation 
at $120 \times \mathrm{g}$ for $5 \mathrm{~min}$. Platelet function was tested using a computerized TEG Hemostasis Analyzer system according to the manufacturer's instructions (TEG 5000; Haemoscope Corporation, Niles, IL, USA). Briefly, citrate plasma was mixed with kaolin, inverted 5 times and loaded in a heparinase-coated cup containing $20 \mu \mathrm{L}$ of $\mathrm{CaCl}_{2}$. TEG was started instantly to record for 1 hour with maximum clot amplitude $\left(\mathrm{MA}_{\text {thrombin }}\right)$, which represents maximum platelet-fibrin clot strength and is affected by changes in platelet count, fibrinogen and function. In addition, other parameters were recorded, including time to fibrin formation (R), clot formation time (K) and angle constant $(\alpha)$. Another sample of heparinized blood was added to a non-heparinase-coated cup in the presence of the activator $\mathrm{F}$ and adenosine diphosphate (ADP, $2 \mu \mathrm{mol}$ ) to generate a whole blood-crosslinked clot with platelet activation $\left(\mathrm{MA}_{\mathrm{ADP}}\right)$, which represented ADP-induced platelet-fibrin clot strength. $\mathrm{MA}_{\mathrm{ADP}}$ was divided into trisections (T1T3) according to one previous study (10), which suggested that cut points between 31 and $47 \mathrm{~mm}$ would be the best predictive values for long-term post-PCI ischemic and bleeding events. A therapeutic range of 31 to $47 \mathrm{~mm}$ for $\mathrm{MA}_{\mathrm{ADP}}$ could provide maximum efficacy and safety.

\section{Statistical analysis}

Continuous variables with normal distributions were expressed as mean \pm SD and categorical variables were summarized by percentages. Categorical variables were compared using $\chi^{2}$ test or Fisher's exact tests. Normal distribution of continuous variables was assessed by the Kolmogorov-Smirnov test. Unpaired two-sides Student's $t$-test was used to compare normally distributed continuous variables between two groups and the one-way ANOVA with least significant difference (LSD) was used to compare among ACS groups (UA, NSTEMI, and STEMI). Spearman's Rho was used to calculate correlation between clot strengths and other hypercoagulability markers in ACS patients. Statistical significance was considered as $\mathrm{P}$ value $<0.05$ or $P$ value $<0.001$. All statistical analyses were performed with SPSS v19.0 software (SPSS Inc., Chicago, Illinois, USA).

\section{Results}

\section{Patient characteristics}

A total of 571 patients, with 145 female patients (25.4\%) and 426 male patients (74.6\%) were included in this study. Among them, 479 patients were ACS (268 of UA, 98 of NSTEMI, and 113 of STEMI), 21 patients were OMI, and 71 patients were healthy subjects in control group. The patients' demographics and characteristics of PCI procedure are described in Tables 1,2, respectively. The average age was $64.1 \pm 10.4$ years. The prevalence of hypertension and hyperlipidemia were similar between groups $(\mathrm{P}>0.05$ for each variable). Laboratory data including platelet counts, hemoglobin and creatinine were well balanced between groups ( $\mathrm{P}>0.05$ for each variable). It is worth noting that more diabetes and smoking patients were found in $\mathrm{CAD}$ patients than non-CAD patients regardless of ACS or OMI $(\mathrm{P} 1<0.05$ and $\mathrm{P} 2<0.001$ for diabetes; $\mathrm{P} 1<0.05$ and $\mathrm{P} 2<0.001$ for smoking). Moreover, majority of OMI and ACS patients received $\beta$-blocker, angiotensin-converting enzyme inhibitor (ACEI)/angiotensin receptor blocker (ARB) and statins, with the proportion much higher than that in nonCAD patients $(\mathrm{P} 1<0.001$ and $\mathrm{P} 2<0.01$ for each variable). In addition, it is obvious that the levels of cardiac troponin-I (cTnI) and brain natriuretic peptide (BNP), which were biomarkers providing CAD prognostic information, were significantly higher in OMI and ACS patients compared with non-CAD patients $(\mathrm{P} 2<0.001$ for $\mathrm{cTnI}$; $\mathrm{P} 1<0.05$ and $\mathrm{P} 2<0.001$ for BNP), especially in patients of STEMI and NSTEMI $(\mathrm{P} 3<0.001$ for $\mathrm{cTnI}$ and BNP) (Table 1). No significant differences were found when considering procedural characteristics among ACS patients (Table 2).

\section{TEG analysis}

As shown in Table 3, higher mean TEG- $\alpha$ and lower mean TEG-K were observed in ACS patients compared with non-CAD patients (P2<0.001 for TEG- $\alpha$ and TEG-K). Meanwhile, the mean value of TEG- $\alpha$ and TEG-K was significantly changed among ACS $(\mathrm{P} 3<0.05$ for TEG- $\alpha$ and TEG-K). Highest level of $\mathrm{MA}_{\text {thrombin }}$ was detected in STEMI patients with the value of $69.4 \pm 4.7 \mathrm{~mm}$, and the value was decreased in turns of NSTEMI, UA, OMI and control group (Table 3, Figure 1A). Lowest $\mathrm{MA}_{\text {thrombin }}$ level was observed in non-CAD patients, which was significantly different from that in ACS or OMI patients $(\mathrm{P} 1<0.05$, $\mathrm{P} 2<0.001$, and $\mathrm{P} 3<0.05$, Figure $1 A$ ). Remarkably, the mean value of $\mathrm{MA}_{\text {thrombin }}$ in STEMI patients was close to the upper normal limit (50 to $70 \mathrm{~mm}$ ), which suggested the state of hypercoagulability after PCI (Figure 1A). The distribution of $\mathrm{MA}_{\text {thrombin }}$ quartiles $(\mathrm{Q} 1$ to $\mathrm{Q} 4)$ of each group in this study is presented in Table 3 and Figure 1B. Hypercoagulability 


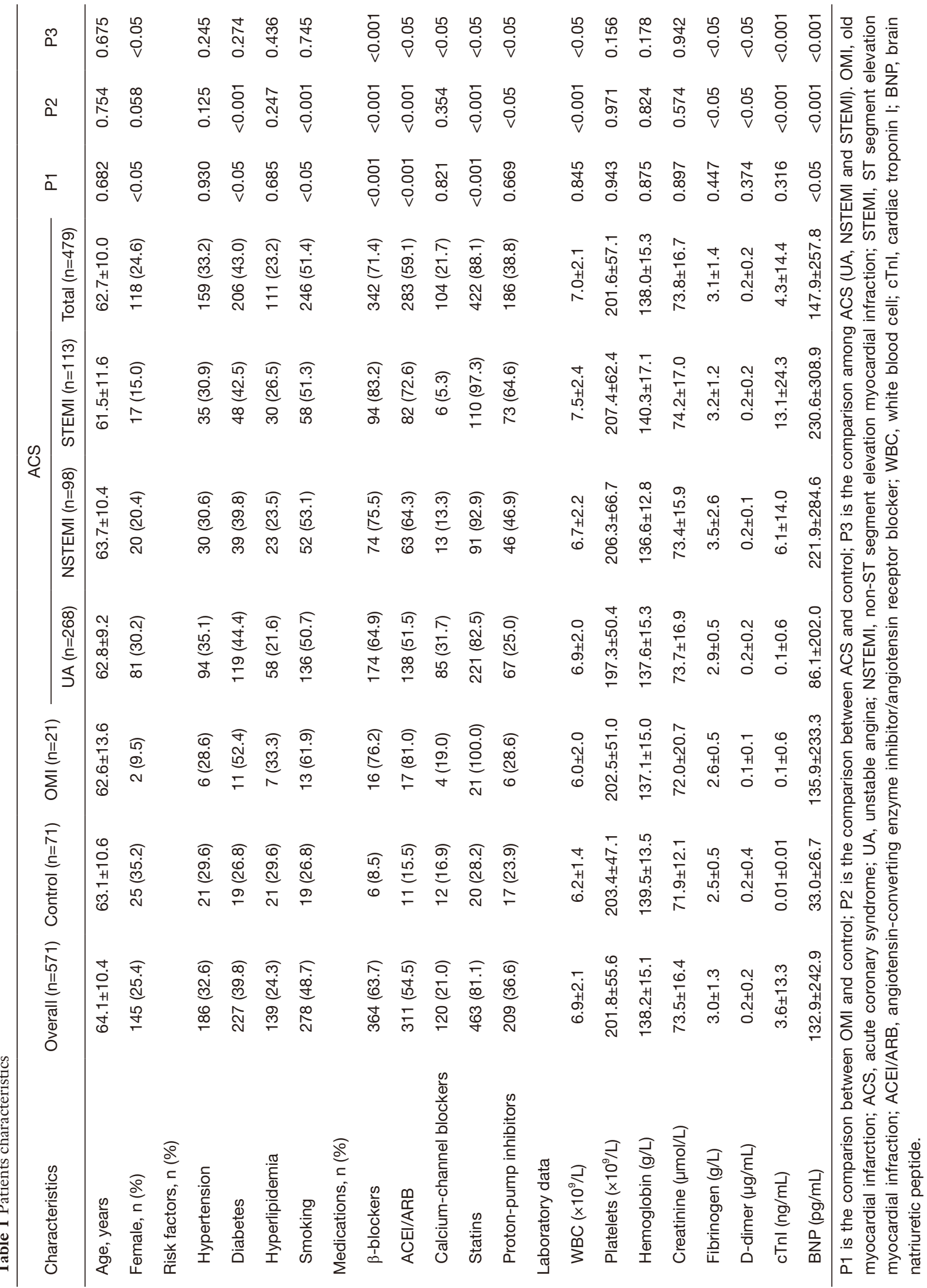


Table 2 Procedural characteristics

\begin{tabular}{|c|c|c|c|c|c|}
\hline Characteristics & \multicolumn{4}{|c|}{ ACS } & $\mathrm{P}$ \\
\hline \multicolumn{6}{|l|}{ Lesion location, n (\%) } \\
\hline Left main coronary artery (LM) & $11(4.1)$ & $6(6.1)$ & $2(1.8)$ & $19(4.0)$ & 0.417 \\
\hline Left anterior descending artery (LAD) & $179(66.8)$ & $63(64.3)$ & $82(72.6)$ & $324(67.6)$ & 0.654 \\
\hline Right coronary artery (RCA) & $105(39.2)$ & $42(42.9)$ & $52(46.0)$ & $199(41.5)$ & 0.526 \\
\hline Multi-vessel disease & $94(35.1)$ & $44(44.9)$ & $41(36.3)$ & $179(37.4)$ & 0.086 \\
\hline Number of stents & $1.5 \pm 0.9$ & $1.7 \pm 1.1$ & $1.7 \pm 1.0$ & $1.6 \pm 1.0$ & 0.546 \\
\hline Length of stents (mm) & $39.6 \pm 30.2$ & $44.1 \pm 34.2$ & $46.6 \pm 30.3$ & $42.2 \pm 31.2$ & 0.248 \\
\hline
\end{tabular}

$\mathrm{P}$ is the comparison among ACS (UA, NSTEMI and STEMI). ACS, acute coronary syndrome; UA, unstable angina; NSTEMI, non-ST segment elevation myocardial infraction; STEMI, ST segment elevation myocardial infraction.

was considered as a value of $\mathrm{MA}_{\text {thrombin }}$ in the fourth quartile (Q4 >72 mm), which might be a predictor of recurrent ischemic events. Our results found that 19.0\% (91/479) of ACS patients were of hypercoagulability, among which 37 (32.7\%) were STEMI patients, 25 (25.5\%) were NSTEMI patients and $29(10.8 \%$ ) were UA patients (Figure 1B,C). Significant difference was detected between UA patients and other ACS patients $(\mathrm{P}<0.001$ for NSTEMI or STEMI compared to UA, Figure $1 C$ ). Few patients in OMI $(1 / 21,4.8 \%)$ and non-CAD $(0 / 71,0 \%)$ groups showed hypercoagulable state (Figure $1 B$ ).

$\mathrm{MA}_{\mathrm{ADP}}$, which could reflect antiplatelet effects of clopidogrel, was assessed after usage of DAPT for at least 5 days. $\mathrm{MA}_{\mathrm{ADP}}$ was compared among ACS groups, and the results are presented in Table 3 and Figure 2. There was a progressive increase of $\mathrm{MA}_{\mathrm{ADP}}$ in patients with UA, NSTEMI and STEMI. Higher $\mathrm{MA}_{\mathrm{ADP}}$ was observed in STEMI and NSTEMI patients when compared with UA patients $(\mathrm{P}<0.001$, Figure $2 A)$. Meanwhile, values of $\mathrm{MA}_{\mathrm{ADP}}$ was similar between NSTEMI and STEMI patients $(\mathrm{P}=0.193$, Figure $2 A)$. In this study, a considerable portion of $41.8 \%$ ACS patients were in the first trisection $\left(\mathrm{MA}_{\mathrm{ADP}}\right.$ $<31 \mathrm{~mm}$ ), containing $50.4 \%$ of UA patients, $35.7 \%$ of NSTEMI patients and $26.5 \%$ of STEMI patients. Significant difference was observed between UA patients and other ACS patients $(\mathrm{P}<0.05$ for NSTEMI vs. UA; $\mathrm{P}<0.001$ for STEMI vs. UA, Figure 2B). Meanwhile, $27.6 \%$ of NSTEMI and $31.0 \%$ of STEMI patients were in the third trisection $\left(\mathrm{MA}_{\mathrm{ADP}}>47 \mathrm{~mm}\right)$, which was significantly higher than that of UA patients $(12.7 \%)(\mathrm{P}<0.001$ for NSTEMI or STEMI $v$ s. UA, Figure $2 B$ ). For patients in the potential therapeutic window $\left(\mathrm{MA}_{\mathrm{ADP}} 31-47 \mathrm{~mm}\right)$, there was no difference among UA, NSTEMI and STMEI patients, with the proportion of $36.9 \%, 36.7 \%$ and $42.5 \%$, respectively (Figure 2B).

\section{Correlations between fibrinogen and TEG variables}

Weak to moderate correlations between fibrinogen and TEG variables, such as $\mathrm{MA}_{\text {thrombin }}$, TEG-K, TEG-angle, and $\mathrm{MA}_{\mathrm{ADP}}$, were observed in ACS patients (Table 4). Spearman's Rho which measured the strength and direction of the relationship between two variables were 0.404 , $-0.349,0.352$ and 0.235 between fibrinogen and $\mathrm{MA}_{\text {thrombin, }}$, TEG-K, TEG- $\alpha$, and $\mathrm{MA}_{\mathrm{ADP}}$, respectively $(\mathrm{P}<0.001$ for each correlation analysis). Weak corrections between $\mathrm{D}$-dimer and TEG variables were detected (Table 4), with Spearman's Rho being $0.219,-0.148,0.124$ and 0.115 between $\mathrm{d}$-dimer and $\mathrm{MA}_{\text {thrombin, }}$ TEG-K, TEG- $\alpha$, and $\mathrm{MA}_{\mathrm{ADP}}$, respectively $\left(\mathrm{P}<0.001\right.$ for $\mathrm{MA}_{\text {thrombin }}$ and TEG-K; $\mathrm{P}<0.05$ for TEG- $\alpha$ and $\left.\mathrm{MA}_{\mathrm{ADP}}\right)$.

\section{Discussion}

TEG now is widely used for platelet function measurement. Our study sought to describe the difference of TEG results among different manifestations of CAD after PCI. In this study, we found various degrees of hypercoagulability and 


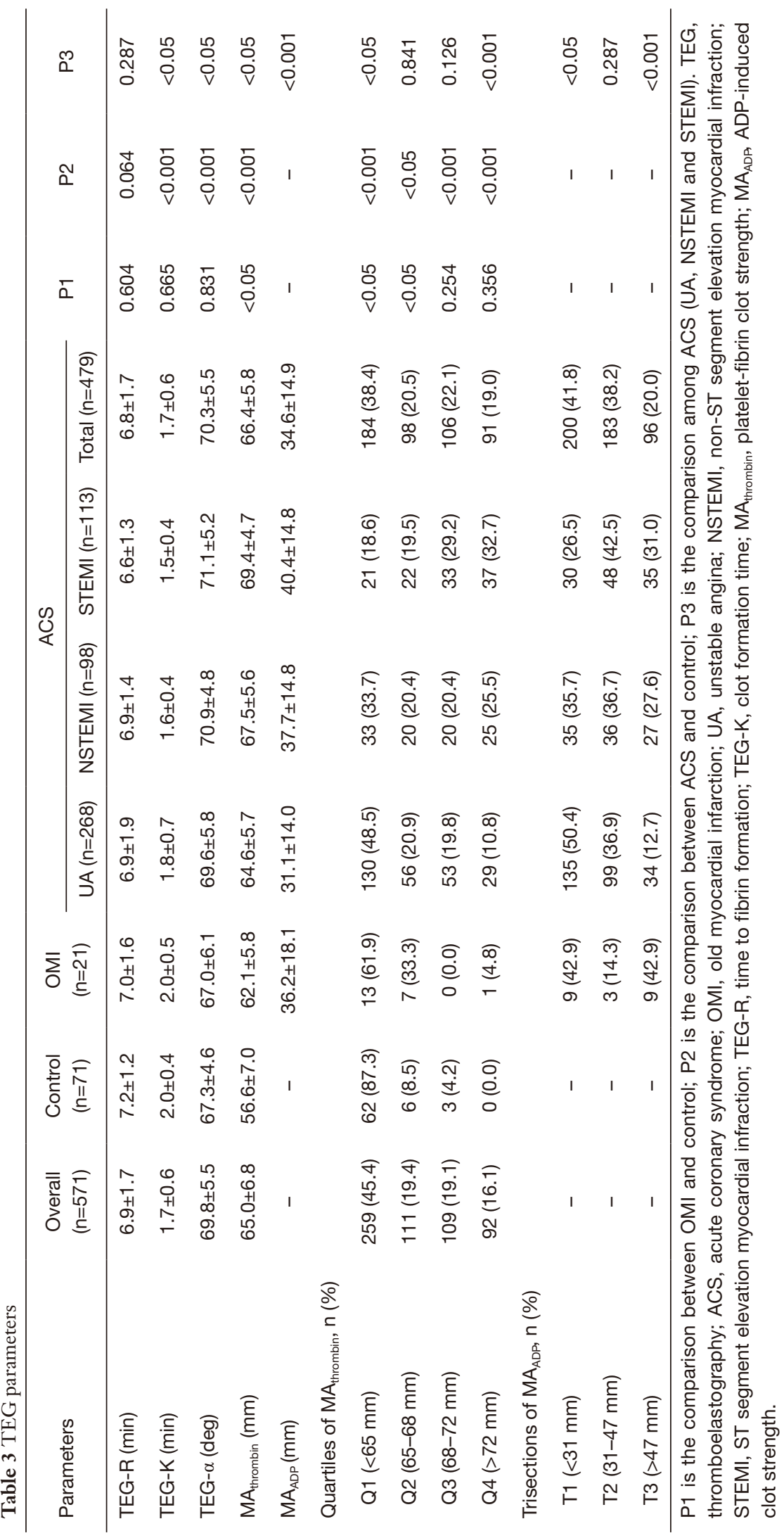



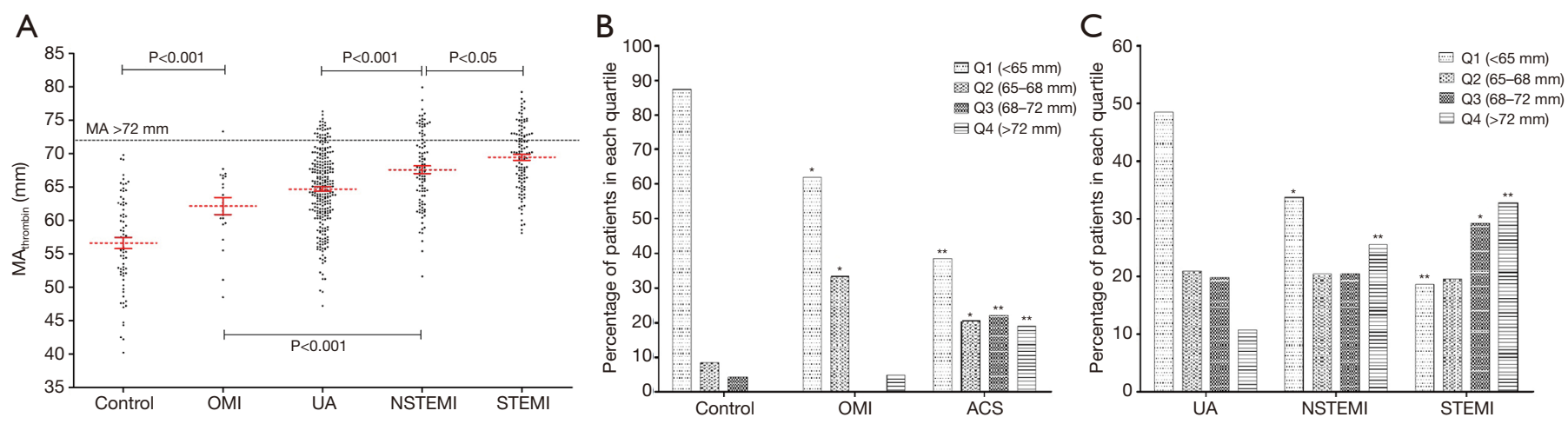

Figure 1 Levels of $\mathrm{MA}_{\text {thrombin }}$ and $\mathrm{MA}_{\text {thrombin }}$ quartiles. (A) MA thrombin among study groups; (B) $\mathrm{MA}_{\text {thrombin }}$ quartiles among control, OMI, and ACS; (C) $M_{\text {thrombin }}$ quartiles among UA, NSTEMI, and STEMI. Control indicates non-coronary heart disease patients; OMI indicates old myocardial infarction patients; UA indicates unstable angina patients, NSTEMI indicates non-ST segment elevation myocardial infraction; STEMI indicates ST segment elevation myocardial infraction patients; ACS indicates acute coronary syndrome patients. * $\mathrm{P}<0.05$; **, $\mathrm{P}<0.001$. $\mathrm{MA}_{\text {thrombin, }}$, platelet-fibrin clot strength.
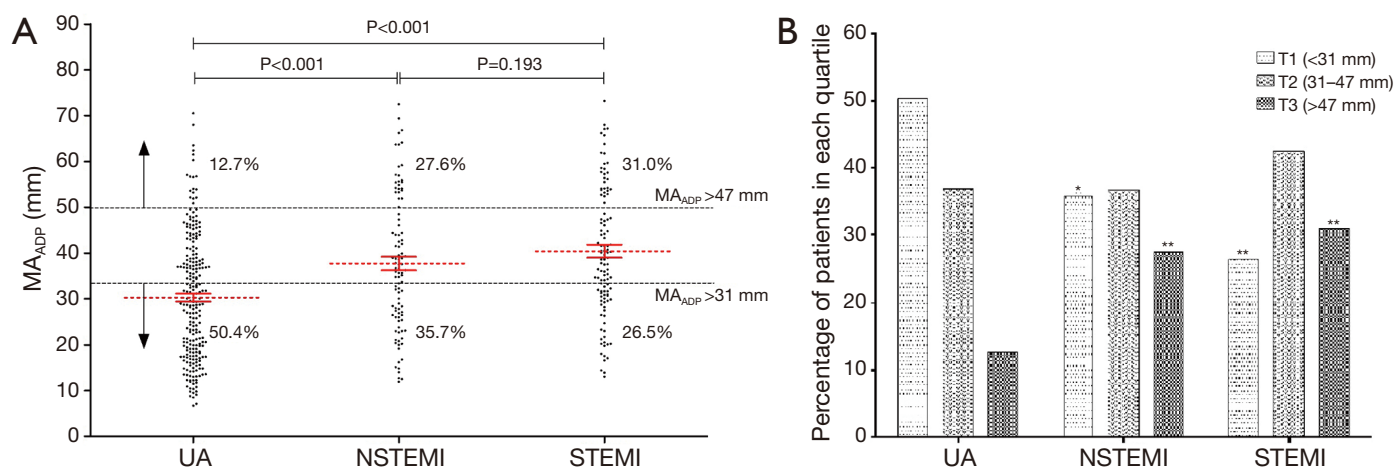

Figure 2 Levels of $\mathrm{MA}_{\mathrm{ADP}}$ and $\mathrm{MA}_{\mathrm{ADP}}$ trisection. (A) $\mathrm{MA}_{\mathrm{ADP}}$ levels among UA, NSTEMI, and STEMI; (B) MA $\mathrm{ADP}$ trisection among UA, NSTEMI, and STEMI. UA indicates unstable angina patients; NSTEMI indicates non-ST segment elevation myocardial infraction; STEMI indicates ST segment elevation myocardial infraction patients. *, $\mathrm{P}<0.05$; ${ }^{* *}, \mathrm{P}<0.001 . \mathrm{MA}_{\mathrm{ADP}}$, ADP-induced clot strength.

antiplatelet effects of clopidogrel among OMI, UA, and ACS (UA, NSTEMI, STEMI). Highest level of MA thrombin was detected in STEMI patients, while lowest $\mathrm{MA}_{\text {thrombin }}$ level was observed in non-CAD patients. Higher $\mathrm{MA}_{\mathrm{ADP}}$ was observed in STEMI and NSTEMI patients when compared with UA patients. Therefore, personalized therapy, i.e., different antiplatelet therapeutic regimens given to $\mathrm{CAD}$ patients according to their hypercoagulability and antiplatelet effects of clopidogrel, should be applied to achieve optimal secondary prevention.

It is well known that post-stent ischemic events are influenced by platelet activation and thrombin generation. Currently, DAPT, consisting of the combination of aspirin and a platelet $\mathrm{P} 2 \mathrm{Y}_{12}$ receptor inhibitor for $\mathrm{ADP}$, is a standard care for patients after PCI. Clopidogrel is the most widely used $\mathrm{P} 2 \mathrm{Y}_{12}$ receptor inhibitor in China. The standard dose of aspirin and clopidogrel was based on the randomized clinical trial of PCI-CURE study (4), which did not assess the pharmacological effects on individuals by means of laboratory tests. Despite the proven benefits of aspirin and clopidogrel therapy, there were still nearly $20 \%$ of poststent patients suffering recurrent ischemic or thrombotic events $(9,11)$. Therefore, it is speculated that personalized antiplatelet therapy according to one's hypercoagulability and antiplatelet effect of clopidogrel might be appropriate for post-stent patients.

TEG, which was specially designed to assess overall clotting kinetics and strength in whole blood, was used 
Table 4 Correlation analysis of white blood counts, fibrinogen, D-dimer and TEG in ACS patients

\begin{tabular}{|c|c|c|c|c|}
\hline Variables & $\mathrm{MA}_{\text {thrombin }}$ & TEG-K & TEG- $\boldsymbol{\alpha}$ & $M A_{A D P}$ \\
\hline Fibrinogen & Rho $=0.404, P<0.001$ & Rho $=-0.349, P<0.001$ & Rho $=0.352, P<0.001$ & Rho $=0.235, P<0.001$ \\
\hline D-dimer & Rho $=0.219, \mathrm{P}<0.001$ & Rho $=-0.148, P<0.001$ & Rho $=0.124, P<0.05$ & Rho $=0.115, P<0.05$ \\
\hline
\end{tabular}

TEG, thromboelastography; ACS, acute coronary syndrome; WBC, white blood cell; TEG-K, clot formation time; TEG- $\alpha$, angle constant; $\mathrm{MA}_{\text {thrombin, }}$ platelet-fibrin clot strength; $\mathrm{MA}_{\mathrm{ADP}}$, ADP-induced clot strength.

in this study to detect hypercoagulable states of poststent patients (12). Various degrees of hypercoagulability and antiplatelet effects of clopidogrel were found among OMI and ACS patients with different manifestations (UA, NSTEMI and STEMI). MA $\mathrm{A}_{\text {thrombin, }}$ one of the characteristics in TEG, could represent the maximal clot strength. An abrupt elevation of $\mathrm{MA}_{\text {thrombin }}$ was found in ACS patients, and the highest level of $\mathrm{MA}_{\text {thrombin }}$ was reported in STEMI patients, which indicated notable hypercoagulability of STEMI patients. It was worth noting that a progressive increase was exist in OMI, UA, NSTEMI and STEMI patients, suggesting that increased $\mathrm{MA}_{\text {thrombin }}$ was associated with the stages of CAD. Similar trend was also found in the values of $\mathrm{MA}_{\mathrm{ADP}}$. $M \mathrm{~A}_{\mathrm{ADP}}$ could reflect platelet reactivity to $\mathrm{ADP}$ and assess the individual patient's response to clopidogrel therapy in this study. Cut points of $\mathrm{MA}_{\mathrm{ADP}}$ were defined as 31 and $47 \mathrm{~mm}$ according to the previous studies, which introduced that $\mathrm{MA}_{\mathrm{ADP}}>47 \mathrm{~mm}$ had the best predictive value of long-term ischemic events regardless of how high the $\mathrm{MA}_{\text {thrombin }}$ might be, and $\mathrm{MA}_{\mathrm{ADP}}<31 \mathrm{~mm}$ was a predictive value for bleeding (10). Therefore, a therapeutic range of $\mathrm{MA}_{\mathrm{ADP}}$ being 31 to $47 \mathrm{~mm}$ was proposed to provide ideal efficacy and safety (10). In this study, 50.4\% of UA patients, $35.7 \%$ of NSTEMI patients and $26.5 \%$ of STEMI patients were in the first trisection $\left(\mathrm{MA}_{\mathrm{ADP}}\right.$ $<31 \mathrm{~mm}$ ), indicating that UA patients might be in a higher risk of bleeding compared with NSTEMI and STEMI patients. About $31 \%$ of STEMI patients and $27.6 \%$ of NSTEMI patients were in the third trisection $\left(\mathrm{MA}_{\mathrm{ADP}}\right.$ $>47 \mathrm{~mm}$ ). The proportion was higher than that of UA patients (12.7\%), suggesting that higher risk of thrombotic events could be predictable in STEMI and NSTEMI patients compared with UA patients. The probable mechanisms could explain these phenomena, of which the exact biologic mechanisms might not be fully understood. UA and NSTEMI are caused by severe coronary lesions and repeated plague ruptures, inducing platelet activation, and enhancing platelet aggregating function in a relative long term. In comparison, coronary plaque rupture leads to platelet aggregating immediately in STEMI, leading to the formation of coronary thrombus (13).

Considering the above factors, "one-size-fits all" strategy has obvious limitations for post-PCI patients, and more attention should be paid to personalized antiplatelet therapy according to individual's hypercoagulability and antiplatelet effects of $\mathrm{P} 2 \mathrm{Y}_{12}$ receptor inhibitors.

It is well known that many factors could affect the ontreatment platelet reactivity, including modifiable factors, such as smoking, high body mass index, drug interactions, as well as non-modifiable factors, such as genetic polymorphisms, age, sex, and chronic kidney disease (14). Besides, both ischemic risk and bleeding risk should also be taken into consideration when choosing antiplatelet drugs for CAD patients. All these factors could contribute to contemplate strategies of tailored antiplatelet regimens that included the use of more potent $\mathrm{P}_{2} \mathrm{Y}_{12}$ inhibitors (14). According to our results, strengthened antiplatelet therapy should be considered in patients with higher ischemic risk and relatively lower bleeding risk. Prasugrel and ticagrelor, as newer $\mathrm{P} 2 \mathrm{Y}_{12}$ receptor inhibitors, could reduce the thrombotic events without significantly increased bleeding events compared with clopidogrel $(15,16)$. Studies also confirmed that few ACS patients (about 3.98\%) using ticagrelor were in $\mathrm{MA}_{\mathrm{ADP}}>47 \mathrm{~mm}$ (17). Accordingly, current clinical guidelines recommended a potent $\mathrm{P} 2 \mathrm{Y}_{12}$ inhibitor (prasugrel or ticagrelor) as a preference to clopidogrel for ACS patients (18). Nevertheless, high on-treatment platelet reactivity also observed in patients with prasugrel and ticagrelor, which correlated with the occurrence of ischemic events (19). Therefore, more exploration is needed in the individualized antiplatelet medication.

Inevitably, there are some limitations in this study. First, this is a single-center observational study. Nevertheless, this study was the first to explore different hypercoagulability and antiplatelet effects of clopidogrel among different manifestations of post-stent patients using TEG. Second, 
the incidence of thrombotic events and bleeding events were not reported, as the long-term follow-up was not conducted in this study. Moreover, the risk factors associated with hypercoagulability and antiplatelet effects of clopidogrel in ACS patients were not evaluated, and the corresponding stratified analysis was not performed. Therefore, a large prospective multicenter, randomized controlled trial is necessary to further validate the present results.

\section{Conclusions}

This study suggested that various degrees of hypercoagulability and antiplatelet effects of clopidogrel existed among OMI, UA, NSTEMI and STEMI patients undergoing PCI. Highest level of $\mathrm{MA}_{\text {thrombin }}$ and $\mathrm{MA}_{\mathrm{ADP}}$ was observed in STEMI patients. Therefore, more attention should be paid to personalized antiplatelet therapy according to individual's hypercoagulability and antiplatelet effects of $\mathrm{P} 2 \mathrm{Y}_{12}$ receptor inhibitors.

\section{Acknowledgments}

Funding: This study was supported by Natural Science Foundation of China (82071238, 81971243), Natural Science Foundation of Jiangsu Province (BK20181459), and China Postdoctoral Science Foundation (2016M591898), Research Funds of Shanghai Health and Family Planning commission (20184Y0022), Cultivation fund of clinical research of Renji hospital (PY2018-III-06), Clinical Pharmacy Innovation Research Institute of Shanghai Jiao Tong University School of Medicine (CXYJY2019ZD001, CXYJY2019QN004), and WU JIEPING medical foundation (320.6750.2020-04-30).

\section{Footnote}

Reporting Checklist: The authors have completed the STROBE reporting checklist. Available at http://dx.doi. org/10.21037/apm-20-1728

Data Sharing Statement: Available at http://dx.doi. org/10.21037/apm-20-1728

Peer Review File: Available at http://dx.doi.org/10.21037/ apm-20-1728

Conflicts of Interest: All authors have completed the ICMJE uniform disclosure form (available at http://dx.doi. org/10.21037/apm-20-1728). The authors have no conflicts of interest to declare.

Ethical Statement: The authors are accountable for all aspects of the work in ensuring that questions related to the accuracy or integrity of any part of the work are appropriately investigated and resolved. The study was conducted in accordance with the Declaration of Helsinki (as revised in 2013). This study was approved by Ethics Committee of Renji Hospital, School of Medicine, Shanghai Jiao Tong University (No.: 2018-025). Written informed consent was obtained from the patients for publication of this study.

Open Access Statement: This is an Open Access article distributed in accordance with the Creative Commons Attribution-NonCommercial-NoDerivs 4.0 International License (CC BY-NC-ND 4.0), which permits the noncommercial replication and distribution of the article with the strict proviso that no changes or edits are made and the original work is properly cited (including links to both the formal publication through the relevant DOI and the license). See: https://creativecommons.org/licenses/by-nc-nd/4.0/.

\section{References}

1. Farag M, Gorog DA. Platelet Function Testing: A Role for Personalised Therapy in Coronary Disease. Curr Pharm Des 2017;23:1315-27.

2. Wu Z, Liu AF, Zhou J, et al. The safety of triple antiplatelet therapy under thromboelastography guidance in patients undergoing stenting for ischemic cerebrovascular disease. $\mathrm{J}$ Neurointerv Surg 2019;11:352-6.

3. Hwang G, Huh W, Lee JS, et al. Standard vs Modified Antiplatelet Preparation for Preventing Thromboembolic Events in Patients With High On-Treatment Platelet Reactivity Undergoing Coil Embolization for an Unruptured Intracranial Aneurysm: A Randomized Clinical Trial. JAMA Neurol 2015;72:764-72.

4. Mehta SR, Yusuf S, Peters RJ, et al. Effects of pretreatment with clopidogrel and aspirin followed by long-term therapy in patients undergoing percutaneous coronary intervention: the PCI-CURE study. Lancet 2001;358:527-33.

5. Steinhubl SR, Berger PB, Mann JT, 3rd, et al. Early and sustained dual oral antiplatelet therapy following percutaneous coronary intervention: a randomized controlled trial. JAMA 2002;288:2411-20. 
6. Gurbel PA, Bliden KP, Guyer K, et al. Platelet reactivity in patients and recurrent events post-stenting: results of the PREPARE POST-STENTING Study. J Am Coll Cardiol 2005;46:1820-6.

7. Kreutz RP, Schmeisser G, Maatman B, et al. Fibrin clot strength measured by thrombelastography and outcomes after percutaneous coronary intervention. Thromb Haemost 2017;117:426-8.

8. Wu H, Qian J, Wang Q, et al. Thrombin induced plateletfibrin clot strength measured by thrombelastography is a novel marker of platelet activation in acute myocardial infarction. Int J Cardiol 2014;172:e24-5.

9. Levine GN, Bates ER, Blankenship JC, et al. 2011 ACCF/AHA/SCAI Guideline for Percutaneous Coronary Intervention: a report of the American College of Cardiology Foundation/American Heart Association Task Force on Practice Guidelines and the Society for Cardiovascular Angiography and Interventions. Circulation 2011;124:e574-651.

10. Gurbel PA, Bliden KP, Navickas IA, et al. Adenosine diphosphate-induced platelet-fibrin clot strength: a new thrombelastographic indicator of long-term poststenting ischemic events. Am Heart J 2010;160:346-54.

11. Bliden KP, DiChiara J, Tantry US, et al. Increased risk in patients with high platelet aggregation receiving chronic clopidogrel therapy undergoing percutaneous coronary intervention: is the current antiplatelet therapy adequate? J Am Coll Cardiol 2007;49:657-66.

12. McCrath DJ, Cerboni E, Frumento RJ, et al. Thromboelastography maximum amplitude predicts postoperative thrombotic complications including myocardial infarction. Anesth Analg 2005;100:1576-83.

Cite this article as: Yan XQ, Zhang C, Shi HY, Kong LC, Liu L, Gu ZC, Zhu Q. Platelet-fibrin clot strength measured by thromboelastography could predict hypercoagulability and antiplatelet effects in patients after percutaneous coronary intervention. Ann Palliat Med 2021;10(3):2448-2457. doi: 10.21037/ apm-20-1728
13. Lv HC, Wu HY, Yin JS, et al. Thrombin induced plateletfibrin clot strength in relation to platelet volume indices and inflammatory markers in patients with coronary artery disease. Oncotarget 2017;8:64217-23.

14. Sibbing D, Aradi D, Alexopoulos D, et al. Updated Expert Consensus Statement on Platelet Function and Genetic Testing for Guiding P2Y12 Receptor Inhibitor Treatment in Percutaneous Coronary Intervention. JACC Cardiovasc Interv 2019;12:1521-37.

15. Wallentin L, Becker RC, Budaj A, et al. Ticagrelor versus clopidogrel in patients with acute coronary syndromes. $\mathrm{N}$ Engl J Med 2009;361:1045-57.

16. Montalescot G, Wiviott SD, Braunwald E, et al. Prasugrel compared with clopidogrel in patients undergoing percutaneous coronary intervention for ST-elevation myocardial infarction (TRITON-TIMI 38): double-blind, randomised controlled trial. Lancet 2009;373:723-31.

17. Li DD, Wang XY, Xi SZ, et al. Relationship between ADP-induced platelet-fibrin clot strength and anti-platelet responsiveness in ticagrelor treated ACS patients. J Geriatr Cardiol 2016;13:282-9.

18. Ibanez B, James S, Agewall S, et al. 2017 ESC Guidelines for the management of acute myocardial infarction in patients presenting with ST-segment elevation: The Task Force for the management of acute myocardial infarction in patients presenting with ST-segment elevation of the European Society of Cardiology (ESC). Eur Heart J 2018;39:119-77.

19. Siller-Matula JM, Trenk D, Schror K, et al. Response variability to $\mathrm{P} 2 \mathrm{Y} 12$ receptor inhibitors: expectations and reality. JACC Cardiovasc Interv 2013;6:1111-28. 